32. All electrostatic determinations of contact forcc are really determinations of the sum of at least three such forces, none of which are knowable separately by this means.

33. The only direct way of investigating contact force is by the Peltier effect or its analogues. [Maxwell.]

34. Zinc and copper in contact are oppositely charged, but are not at very different potentials : they were at different potentials before contact, but the contact has nearly equalised them.

[Certain portions of these statements which may appear wildly hypothetical, such as 13, are to be justified by figures. The justification is not complete, for lead and iron are untractable, but it does not affect the main position.]

\section{THE AMERICAN ASSOCIATION}

$\mathrm{WE}^{\mathrm{E}}$ are indebted to the courtesy of the Fditor of Science for the following reports of the Sectional proceedings of the American Association.

In the Section of Physics a paper was read on "The Relation of the Yard to the Metre," by Prof. William A. Rogers, who has given his life to perfecting the construction and the testing of standards of length, and the result of this his latest investigation is that the metre is $39^{\circ} 37027$ inches in length. One of the most important physical measurements is that of the wavelength of light of any given degree of refrangibility, and this determination is best made by means of the diffraction grating. On account of the extensive use of the magnificent gratings constructed by Prof. Rowland for this purpose, Prof. Rogers instituted an investigation to determine the coefficient of expansion of the speculum-metal used in the construction of these gratings. He also noted that from its homogeneity, fineness of grain, and non-liability to tarnish, this speculum-metal is peculiarly suitable for constructing fine scales, though its extreme brittleness is an objection to its use for large scales.

Prof. Rowland stated that he proposed to construct scales on his ruling-engine which would enable the physicist at any time, by purely optical means, and without knowing the coefficient of expansion of the metal or its temperature, to obtain the value of the length of the scale in terms of the wave-length of any given ray of light. These scales were simply to be straight pieces of specuhm-netal ruled with lines just as an ordinary grating, except that the length of the lines is to be only about one centimetre, every one-hundreth line being somewhat longer than its neighbours : the whole ruled slip is to be one decimetre in length. From the manner of ruling, it will be easy to count the whole number of lines in the length of the strip, and then by a simple use of the scale as a grating, in a suitable spectrometer, the whole length may be immediately found at any time in terms of any specified wave-length of light. In some forms of telephones and in the microphone the action depends on the change in resistance of a small carbon button on being subjected to pressure. There has been much discussion as to whether this diminution of the resistance with pressure is due to a change in the resistance of the carbon itself, or simply to the better contact made between the carbon and the metallic conductor when the pressure is applied.

Prof. Mendenhall has carried out some experiments to determine the question ; and one of his methods of experimentingthat with the hard carbons-appears to point conclusively in favour of the theory that the resistance of the carbon itself is altered by pressurc. The experiments made by him on soft carbon are open to criticism, though they also point to the change taking place in the carbon. Prof. Mendenhall finds that the resistance is not simply proportional to the pressure, and thinks that by increasing the pressure a point of maximum conductivity would be reached where there would be no change in resistance for a small change in pressure.

Prof. A. Graham Bell, the inventor of the telephone, read a paper giving a possible method of communication between ships at sca. The simple experiment that illustrates the method which he proposed is as follows:- Take a basin of water, introduce into it, at two widely-separated points, the two terminals of a battery circuit which contains an interruptor, making and breaking the circuit very rapidly. Now at two other points touch the water with the terminals of a circuit containing a telephone. A sound will be heard, except when the two telephone terminals touch the water at points where the potential is the same. In this way the equipotential lines can easily be picked out. Now, to apply this to the case of a ship at sea : Suppose one ship to be provided with a dynamo-machine generating a powerful current, and let one terminal enter the water at the prow of the ship, and the other be carefully insulated, except at its end, and be trailed behind the ship, making connection with the sea at a considerable distance from the vessel; and suppose the current be rapidly made and broken by an interruptor; then the observer on a second vessel provided with similar terminal conductors to the first, but having a telephone instead of a dynamo, will be able to detect the presence of the other vessel even at a considerable distance; and by suitable modifications the direction of the other vessel may be found. This conception Prof. Bell has actually tried on the Potomac River with two small boats, and found that at a mile and a quarter, the farthest distance experimented upon, the sound due to the action of the interruptor in one boat was distinctly audible in the other. The experiment did not succeed quite so well in salt water.

Prof. Trowbridge then mentioned a method which he had suggested some years ago for telegraphing across the ocean without a cable; the method having been suggested more for its interest than with any idea of its ever being put in practice. A conductor is supposed to be laid from Labrador to Patagonia, ending in the ocean at those points, and passing through New York, where a dynamo-machine is supposed to be included in the circuit. In Europe a line is to extend from the north of Scotland to the south of Spain, making connection with the ocean at those points; and in this circuit is to be included a sensitive galvanomcter. Then any change in the current in the American line would produce a corresponding change in current in the Europcan line; and thus signals could be transmitted.

Mr. W. H. Preece then gave an account of how such a system had actually been put into practice in telegraphing between the Isle of Wight and Southampton during a suspension in the action of the regular cable communication. The instruments used were a telephone in one circuit, and in the other about twenty-five Leclanché cells and an interruptor. The sound could then be heard distinctly; and so communication was kept up until the cable was again in working order. Of the two lines used in this case, one extended from the sea at the end of the island near Fiurst Castle, through the length of the island, and entered the sca again at Ryde; while the line on the mainland ran from Hurst Castle, where it was connected with the sea, tbrough Southampton to Portsmouth, where it again entered the sea. The distance between the two terminals at Hurst Castle was about one mile, while that between the terminals at Portsmouth and Ryde amounted to six miles.

A few years ago Mr. E. H. Hall, then a student at the Johns Hopkins University, taking a thin strip of gold-leaf through which a current of electricity was passing, and joining the two terminals of a very sensitive galvanometer to two points in the gold-leaf, one on one edge, and the other on the other, choosing the points so exactly opposite that there was no current through the galvanometer, found that on placing the poles of a powerful electro-magnet, one above and the other below the strip of goldleaf, he obtained a current through the galvanomcter, thus indicating that there was a change in the electric potential, due to the action of the magnet. Mr. Hall explains this change by supposing the rotation of the equipotential lines in the conductor about the lines of magnetic force. This explanation has been brought into question by Mr. Shelford Bidwell, who attempts to explain the action thus : the magnetic force acting on the conductor carrying the current would cause the conductor to be moved sidcways, were it free to move; but, since it is held by clamps at the ends, the magnetic force acting upon it brings it into a state of strain, one edge being compressed and the other stretched; and Mr. Bitlwell supposes the whole Hall effect to be due to thermal actions taking place in consequence of this unsymmetrical state of strain. Prof. Hall, who is now at Harvard, has made some careful experiments to test this explanation of Mr. Bidwell. He used not only gold-leaf, but strips of steel, tinfoil, and other metals, and clamped them sometimes at both ends, sometimes in the middle, and sometimes only at one end; and in all cases the action was the same, with the same metal, irrespective of the manner of clamping. This was strong evidence against Mr. Bidwell's position.

Sir William Thomson suggested, as a further test to bring about the state of strain, which Mr. Bidwell supposes to be the primary cause of the action, by purely mechanical means, bring 
ing pressure to bear on one side or the other, and seeing whether the action obtained is at all commensurate with the action found by Mr. Hall.

Prof. Hall then discussed an experiment by which $\mathrm{Mr}$. Bidwell had obtained a reversal of the effect, and showed that the reversal was only apparent, and that when carefully examined the results of Mr. Bidwell's experiments were best satisfied by the theory of the rotation of the equipotential surfaces about the lines of mannetic force.

Sir William Thomson spoke of the discovery of $\mathrm{Mr}$. Hall as being the most important made since the time of Faraday. He favoured Mr. Hall's explanation, though he considers Mr. Bidwell's suggestion as very important, and thinks that it will very likely be found that both the Hall effect and thermal effects have a common cause, rather than that one is to be taken to explain the other. He showed also that the mathematical examination of the subject indicates three relations to be investigated,-- first, the relation of thermal force to the surfaces of equal rate of variation of temperature; second, the relition of electric current to the equipotential surfaces; third, the relation of the thermal flow to isothermal surfaces. The second of these is that investigated by Mr. Hall, who has found that under the conditions mentioned the lines of flow are not pexpendicular to the equipotential surfaces. There remains, therefore, "work for two more Halls," in either proving or disproving the existence of the analogous actions in these other two cases. Sir William Thomson also suggested the following exceedingly interesting mechanical illustration or analogue of Hall's effect. Let us be living upon a table which rotates uniformly for ever. A narrow circular canal is upon this table, concentric with the axis of rotation of the table, and nearly full of water. After a while the water will acquire the same velocity of rotation as the table, and wili come to a state of equilibrium. The outer edge of the water in the canal will then stand a little higher than the inner edge. Let us now apply a little motive force to the water, and by means of a pump cause it to flow in the canal in the same direction in which the table is already rotating: it is evident that it will stand higher on the outer edge, and lower on the inner edge of the canal, than before. But, should we cause it to flow in the opposite direction to the motion of the table, it will stand lower on the outer edge, and higher on the inner edge, than in its position of equilibrium. The experiment made by Mr. Shelford Bidwell may also be illustrated by putting a partition in the canal so as to divide it into two circular concentric troughs, and make a little opening in the partition at some point; then taking two points near the opening in the partition, one in one trough and one in the other, if they are very close to the partition, the point in the outer trough will be at a lozver level than that in the inner one; but if they are not close to the partition, but one is taken close to the outer edge of the outer trough and the other close to the inner edge of the inner trough, then the point in the outer trough will be at a higher level than that in the inner trough, though the difference in level will be only about half of what it would have been had there been no partition separating the canal into two troughs.

Prof. Forbes called attention to the fact that the classification of the metals according to their thermo-electric qualities gives not only exactly the same division into positive and negative, but that the very order obtained in that way corresponds to that obtained by classifying according to the IIall effect, except possibly in the casc of aluminium.

In the Section of Mathematics and Astronomy the first paper read was by Prof. E. C. Pickering, upon the colours of the stars. The need of exact photometric measurement of different parts of their spectra was first pointed out, and the author then described a very ingenious method of accomplishing this. In the telescope tube, a little beyond the focal plane, is a directvision prism, so set as to give a spectrum extended in declination; and on the preceding side of this prism is placed a piece of plane glass, whose edges are so ground that, when a small $p$ rtion of the following side of the cone of rays falls upon it, it gives a small white ghost, just preceding the spectrum and always opposite the same wave-length. In the focal plane is one of Prof. Pritchard's nentral-tint wedge photometers, and behind it a thin metal diaphragm with four long, narrow slits parallel to the equatorial motion; so that, when the spectrum transits behind them, four little stars-a red, yellow, blue, and a violet-shine through these slits, and the time of the disap- pearance of each, as they move towards the thicker edge of the wedge, measures its brightness. From these times may be deduced the magnitude and colour curve of the star. To fix the same wave-lengths for each observation, the little white ghost is adjusted upon one of two parallel wires which project out beyond the preceding side of the diaphragm. For a succeeding transit, the ghost is adjusted upon the other wire, half a slit-interval distant, and thus eight points of the spectrum are photometrically measured.

Prof. Young of Princeton spoke very highly of the ingenuity and effectiveness of the device, especially for the systematic measurement of a large number of stars. He pointed out, however, what might be a source of error, viz. the different sensitiveness of different observers' eyes to different colours, so that they would probably observe the times of disappcarance of the four coloured stars slightly relatively different.

The next paper, by Prof. 1)aniel Kirkwood, discussed the question whether the so-called "temporary stars" may be variables of long period, referring to the sometimes-claimed identity of the temporary stars 945 and 1264, with the wellknown Tycho Brahe's star, which blazed forth in Cassiopeia in $\mathbf{I} 572$, and whose position is pretty closely known from his measures. The conclusion reached was, that on account of the sudden apparition of the temporary stars, the short duration of their brightness, and the extraordinary length of their supposed periods, they should be considered as distinct from variables.

Prof. Mansfield Merriman, the author of the well-known treatise on "Least Squares," proposed a criterion for the rejection of doubtful observations, founded upon Wagen's demonstration of the law of frequency of error, which was simpler than Piercc's or Chauvenet's. It involves, however, a determination of what is the unit of increment between errors of different sizes, a thing difficult to determine in very many cases.

Prof. Pickering then read another paper upon systematic errors in stellar magnitudes, showing, without any question, that the magnitudes of all the star-catalogucs, from that of Ptolcmy down to the great work of Argelander in the Durchmusterun - all: depending upon eye-estimates-are systematically affected by being in, or close to, the Milky Way; they all being estimated too faint, and the error amounting to about half a magnitude in the Milky Way itself. This arises from the brightness of the background upon which the star is viewed. In the Harvard photometry measures, this source of error is avoided, since, in the comparison of each star with the PoleStar, the two fields are superposed, and their added brightness affects both stars alike.

Prof. M. W. Harrington, Director of the Ann Arbor Obscrvatory, read a paper upon the asteroid ring. He showed that the representative average orbit would be an ellipse of small eccentricity, with semi major axis equal to about $2 \cdot 7$ times that of the earth, and inclined to the plane of the ecliptic about $\mathrm{I}^{\circ}$; and that, in the progressive discovery of these small bodies, the average mean distance had gradually increased, but now seemed to have reached its limit. On the assumption that the surfaces of all the asteroids have the same reflecting power as Vesta, Prof. Harrington reaches the conclusion that the volume of $\mathrm{V}$ csta is about $5 / 17$ that of all these 230 bodies put together, and that Vesta and Ceres together form almost one-half the total volume.

Prof, Rogers, of the Harvard College Observatory, read two papers. The first, upon the magnitude of the errors which may be introduced in the reduction of an observed system of stellar co-ordinates to an assumed normal system by graphic methods, showed a great amount of laborious research, and was a good illustration of the vast amount of monotonous work necessary in the present stage of astronomical obscrvation in order to reach the highest degree of accuracy attainable by the search for and climination of minute systematic errors. His next paper was upon the original graduation of the Harvard College meridian circle in sitw. This described a method of turning a meridian circle through any desired constant arc up to about $30^{\circ}$ without any dependence upon the circle and reading microscopes, effected by means of an arm swinging between fixed stops, and clamping to a circular ring on the axis by an electro-magnetic clamp. With this Prof. Rogers claimed to be able to set off a constant arc through as many as five thousand successive movements of the clamping arm. The irigenious method suggested and carried out by Mr. George B. Clark, of the firm of Alvan Clark and Sons, of grinding the clamping circle to a perfect circular form while the telescope was swung round in its Y's was 
fully described, and also Prof. Rogers' method of arresting the momentum of the telescope at the stops by water-buffer plungers. The great advantage of thus being able to set off a constant arc independent of the circle and microscopes was pointed out, with especial reference to the investigation of division errors and flexure of circle, and also to the division of the circle itself in situ; i.e. mounted on its axis and turning on its pivots.

Prof. Young called attention to the necessity of guarding against expansion and contraction of the bar holding the stops, due to radiation from the observer's body.

Mr. S. C. Chandler, Jun., of the Harvard College Observatory, gave the results of observations and experiments with an "almucantar" of four inches' apcrture, a new instrument devised by Mr. Chandler, which scems to be of remarkable accuracy, and promises to furnish an entirely new and independent method of attacking some of the most important problems in exact observational astronomy. The instrument consists of a telescope and vertical setting-circle, which can be clamped at any zenith-distance, and is supported on a rectangular base which floats in a rectangular trough of mercury, the whole turning round a vertical axis so as to observe in any azimuth; these observations being simply the times of transit of any heavenly body over a system of horizontal wires in the field. The observations thus far have been entirely upon stars, and all at the apparent zenith-distance of the pole. After some very small periodic variations in the zenith-distance pointing had been traced to changes of temperature, and had been removed by sawing through the wooden bottom of the mercury trough, the instrument showed an astonishing constancy in this zenith-distance pointing, extending over weeks at a time, and far exceeding the constancy of the corrections to the best fundamental instruments of our observatories.

A paper was read by Mr. Chandler, upon the colours of variable stars. Showing, first, that most of the variables were red, he described some fairly satisfactory methods which he had used to measure the degree of redness of all the periodic variables; and then, plotting a series of points whose abscissæ represented the length of the periods, and ordinates the deoree of retness, their agreement with a curve making a very decided angle with the axis of abscissæ brought out without question the remarkable law that the redder the star the longer is its poriod of variability. In discussing any theory of variable stars, $\mathrm{Mr}$. Chandler pointed ont that Zöllner was the only one who had thus far taken into account two laws already known, viz. (I) that they are generally red; (2) that they increase in brightness much more rapilly than they itcrase; and now, in any further theory, this new third law must have a place, viz. that the redder they are the longer is their period.

Dr. R. S. Ball, Astronomer-Royal for Ireland, read a paper upon the ruled cubic surface known as the cylindroid, whose equation is

$$
z\left(x^{2}+y^{2}\right)-2 m x y=0 .
$$

Mr. W. S. Auchencloss of Philadelphia exhibited a balancing machine for finding the centre of gravity of any number of different weights distributed along a line, which seemed to be of excellent construction, extremely easy and rapid in manipulation, and quite sensitive. In connection with a time-scale of 365 days at one side, it was shown how rapidly a complicated system of business accounts could be settled, and how it could be applied to various engineering problems.

Prof. J. H. Gore, of the U.S. Geological Survey, read a paper upon the geodetic work of the U.S. Coast and Geodetic Survey.

The next paper was by Mr. J. N. Stockwell of Cleveland, upon an analysis of the formula for the moon's latitude as affected by the figure of the earth. In this Mr. Stockwell claimed that Laplace's formula for expressing this was wrong; the question turning upon an approximate integration of a differential equation, which he claimed to show was wrong by separating into two terms a single one which expressed the difference of two effects, which, thus evaluated separately, became either indeterminate or of an impossible amount.

Prof. J. C. Adams of Cambridge, England, made some comments upon Mr. Stockwell's paper, speaking in high terms of the general work which Mr. Stockwell had done in the difficult subject of the lunar theory; but from such conclusions and methods as those brought forward in this particular case he said he must express his total dissent. He then pointed out that this cquation was, to begin with, only an approximation; that, before it could be treated at all as a rigorous one, many other small terms must be included ; that, further, its integration was only an approximation; and that in this case any separation into terms, which, on a certain approximate assumption, became either indeterminate or very large, was of no value as a test of the equation.

Prof. Ormond Stone, Director of the Leander McCormick Observatory of the University of Virginia, gave an elaborate description of that Observatory, now approaching completion, and to be devoted entirely to original research. The telescope, which will soon be mounted, is the twin in size of the Washington 26 -inch, and like it in most of its details, except that the driving clock is like that of the Princeton 23-inch, with an auxiliary control by an outside clock, and that it has Burnham's micrometer illumination. The Observatory has a permanent fund of 76,000 dollars as a beginning, and 18,000 dollars have been expended in Observatory buildings, and 8000 dollars for the house of the Director. Siluated 850 feet above the sea, and on a hill 300 feet above surroundings, the main building, circular in shape, is surmounted by a hemispherical dome 45 feet in diameter. The brick walls have a hollow air-space, with inward ventilation at bottom and outward at top.

Mr. Warner, the builder of the dome, gave an interesting description of the ingenious method of adjusting the conical surfaces of the bearing-wheels, so that they would, without guidance, follow the exact circumference of the tracks; and then of the adjustment of the guide-wheels, so that the axis of this cone should be exactly normal to the circular track. The framework of the dome consists of thirty-six light steel girders, the two central parallel ones allowing an opening six feet widc. The covering is of galvanised iron, each piece fitted in situ, and the strength of the frame is designed to stand a wind-pressure of a hundred pounds per square foot. There are three equal openings with independent shutters, the first extending to the horizon, the second beyond the zenith, and the third so far that its contre is opposite the division between the first and second. The shutters are in double-halves, opening on horizontal tracks, and connected by endless chain with compulsory parallel motion of the ends. The dome weighs twelve tons and a half, and the livering one ton and a half, and a tangential pressure of about forty pounds, or eight pounds on the endless rope, suffices to start it. If this case of motion continues as the dome grows old, it is cer. tainly a remarkable piece of engincering work.

In the discussion following, Prof. Hough thought he should prefer the old style of single opening extending beyond the zenith.

Prof. Stone could not agree with him, the greater extent of opening making it less probable that the dome would have to be moved so far in turning from star to star, and at the same time furnishing better ventilation, and the opportunity for crossbracing adding strength to the dome. He stated that he should first take up the remeasurement of all the double stars of less than $2^{\prime \prime}$ distance between $0^{\circ}$ and $-30^{\circ}$.

The Rev. Father Perry, the Director of the Observatory at Stonyburst, England, gave the result of late researches on the solar surface, with special reference to evanescent spots.

Mr. Lewis Swift, Director of the Warner Observatory at Rochester, N.Y., read a paper upon the nebulie, in which he described his method of search for new nebula. One very interesting statement of Mr. Swift, to the effect that there had not been a first-rate clear sky since the red glows appeared a year ago following the Krakatoa explosions, bears out the general experience of workers in other observatories, especially those who try to sec stars near the sun in the daytime.

An interesting discussion arose as to the much-disputed existence of the ncbula round the star Merope in the Pleiades; the general drift of it being that the ncbula no doubt cxisted, but in order to see it a clear sky was necessary, and a very low power and large field, so that the nebula might be contrasted with darker portions of the same field ; that a large telescope was not necessary, in fact the smaller the better, provided the optical qualities were relatively as good. Mr. Swift said he could always see it under favourable conditions; and Mr. E. E. Barnard, of Nashville, Tenn., the discoverer of the latest comet, said that before he knew of its existence at all, he picked it up as a supposed comet.

Prof. Adams of Cambridge, England, read a paper upon the general expression for the value of the obliquity of the ecliptic at any given time, taking into account terms of the second order. The difficulties of obtaining a formula for this quantity, on 
account of the many varying elements upon which it depends, were clearly explained by a diagram, and the results given of an approximation carried much further than ever attempted heretofore.

Prof. Harkness, in paying a high compliment to the celebrated mathematician and astronomer for these laborious and valuable researches, also expressed a wish that some of the n-dimensional-space mathematicians would follow the example of Prof. Adams, and apply some of their superfluous energy to the unsolved problems in the solar system, which have some direct practical bearing.

Prof. Newcomb, in remarking upon the mass of the moon used in this problem, expressed the opinion that this could be obtained most accurately by observations of the sun, in determining the angular value of the radius of the small circle described by the earth about the common centre of gravity of earth and moon, since this, in his opinion, seemed to be the only constant which could be determined by observation absolutely free from systematic errors, and hence was capable of an indefinite degree of accuracy by accumulated observations; and he asked Prof. Adams's opinion on this point.

The latter replied that he thought the quantity too small for certain accurate determination, almost beyond what could be actually seen by the eye in the instruments used.

Prof. Newcomb admitted, in the case of absolute determinations, the general impossibility of attempting to measure what cannot be seen, but, in the case of differential or relative determinations in which there was no supposed possibility of constant or systematic errors, he advanced the theory, which he had some thought of elaborating more fully at some time, that such determinations might be carried by accumulated observations to a sure degree of accuracy far beyond what can be seen or measured by the eye absolutely.

Prof. Adams hoped he would more fully elaborate and publish this idea, since there was in it an element well worth careful consideration.

Prof. Harkness doubted the sufficient accuracy of meridian observations of the sun, on account of the distortions produced by letting the sun shine full into the instrument; and spoke of the difficulties in the transit of Venus observation; from this cause.

Prof. Newcomb replied that he would have to show that this would be periodic with reference to the moon's quarters in order to affect this constant systematically.

Prof. Adams then presented another note upon Newton's theory of atmospheric refraction, and on his method of finding the motion of the moon's apogee.

In the Section of Chemistry papers were read by C. F. Mabery of Cleveland, O., on chloropropiolic acid and some derivatives of, acrylic and propionic acids ; and by C. W. Dabney on anhydrobenzamidosalicylic acid.

Dr. Springer of Cincinnati exhibited some improved torsion scales and balances. One of these had been used by Prof. F. W. Clarke, and its action was spoken of as being very satisfactory.

Messrs. L. M. Norton and C. F. Presscott read a paper on continuous etherification ; and Prof. Monroe detailed result; of analyses of an efflorescence on the bricks of some new buildings. It was chiefly sodium sulphate.

Mr. Clifford Richardson, in a paper on the chemistry of roller-milling of wheat, stated that the dark colour of northwestern hard winter wheat could be overcome by using steel rollers run at different speeds.

Prof. Atwater has examined the nutritive value of different fish. He finds flounder to be the least value, and salmon the highest, and in invertebrates the oyster takes the lowest place as a food-stuff.

A lengthened discussion took place on the subject of valence in chemistry. Prof. Clarke remarked that it was especially useful in organic chemistry in explaining isomerism and in synthesis. It was also used in mineralogy; and he mentioned as examples of isomerism the three minerals kyanite, andalusite, and fibrolite, giving the structural formula for each. He then took up the questions of variable valence, invariable valence, and maximum valence as points that misht be discussed. He remarked, further, that valence was an attempt to explain the arrangement of the atoms in a molecule, and spoke of the draw back of being obliged to represent them on a plane surface, space of three dimensions being much nearer the true state of affairs.
Prof. B. Silliman remarked that the last statement of Prof. Clarke was the key to the whole difficulty about valence. A plane surface is insufficient to explain the facts. He testified to the great utility of valence, and spoke of the chaotic condition of organic chemistry before this question of valence was appreciated. It was a working hypothesis, a scaffold without a building, but not the building. Hypothesis is not always the truth.

Prof. W. Ramsay said that the difficulties about valence could be traced to Lavoisier, who worked upon stable compounds, as oxides, chlorides. He also thought that a study of the heat of formation of many compounds would be a key to the valence of the elements; and said that the difficulties of conceiving of the motions of the atoms was well illustrated in Sir William Thomson's effort to explain them in complicated vortex evolutions,

Mr. A. H. Allen called attention to the failure of chemists to recognise the value of the work of John Newlands, in the periodic classification of the elements usually ascribed to Mendeléeff.

Prof. Greene rcmarked that, it was best to consider the cause of valence.

Prof. Ira Remsen testified to the utility of valence. He remarkerl that there were two ways of teaching: one by giving all the principal theories first, and the other giving the facts and then the theories-which latter he considered the best method. He had come to the conclusion that valence should never be mentioned until all the important properties of a compound are known. In regari to its value to young students, he thought its use was dangerous until they fully understood its meaning. $\mathrm{He}$ believed that the value of valence had been magnified, and that it was better to study the reactions of compounds, and the methods for their synthesis, and the manner of breaking up.

$\mathrm{Mr}$. A. H. Allen said that many formulæ that showed the structure of compounds according to the valence of the elements do not give any idea of the true constitution of these compounds as ascertained from a knowledge of their properties. He gave, as examples of his meaning, potassic dichromate and fuming sulphuric acid.

Prof. Dewar, of Cambridge, England, maintained that the graphical method and structural formula were most useful, but they are often presented in a way that shows an incomplete knowledge of the ideas of the person who devised the formula. $\mathrm{He}$ remarked that the text-books contained too many pictures of graphical formulæ, and that he considered it better to follow the historical method for developing theory.

Prof. Atwater thought that some idea of valence should be given at the beginning, as it assisted the student's memory.

Prof. W. Ramsay said that he was satisfied of the utility of making the student perform experiments that brought out facts to illustrate the theory of valence, so that he could thus understand its meaning from his own work.

Prof. Caldwell said that he could not get along with students in chemical analysis who had not obtained some idea of the theory of valence.

Prof. Remsen thought that the theory of valence might be some good as an assistance to the memory; but such assistance was of doubtful value, and too empirical.

Prof. J. W. Langley, Vice-President, said that valence, or chemism, may be a force emanating from the atom, or it may be a force outside the atom; it is static, or dynamic, and a knowledge of it was more a physical than a chemical problem. From the educational view he thought it better to use the theory of valence in connection with the history of the theories concerning atoms and molecules. As a further step, the language and figures of magnetism might be used.

Prof. Stewart described a process of making leather by treating hides with sulphurous acid under pressure.

Prof. Atwater has grown pease in washed sea sand, and found them to gain from 35 to 50 per cent. more nitrogen than they contained originally, and refers this increase to nitrogen directly absorbed from the air.

Dr. Springer, in a paper on fermentation, showed that a fermont exists in the stems of tobacco plants whith decomposes nitrates and forms butyric acid from sugar: solutions.

Prof. Dewar spoke of the density of solid carbonic acid, which he finds to be $\mathrm{r} \cdot 58$ to $\mathrm{I} \cdot 60$.

Other short communications were made by Prof. Munroe on deliquescence; on human milk, by Prof. Leeds; on gas analysis, by Dr. Elliott; and on fish oils, by Mr. Allen. 
The most interesting discussion was on educational methods in laboratories and chemical lectures, by Prof. Remsen, who remarked that in Germany the student does not go into the laboratory until he understands reactions, while in England and the United States he is placed there at the beginning of the course. Prof. Remsen follows an order of instruction in which the student becomes first acquainted with apparatus and methods of manipulation. $\mathrm{He}$ next makes gases, and repeats lecture experiments. He then experiments on oxidation and reduction. Next follows the quantitative analysis of air. Then come alkalimetry and acidimetry, with success. This practical work and the lectures occur simultaneously, and by the time the lecturer has reached the metallic elements, the students are ready to take up test-tube reactions with profit. During the first year the student should only just begin analysis. After the general properties of the metals are known, let the student devise methods of separation. The course of instruction in our colleges l'rof. Remsen regards as too short and superficial. Lecture-experiments should never be made for show. IEsthetics and chemistry are entirely distinct.

Prof. Atwater said that chemistry is taught now, as a rule, after the student has acquired the methods of the classics and has ncver been taught to observe facts. Chemists must show that their science will give what is called "liberal culture," or it will not find a place in our educational institutions. Present methods are not doing this, as they fail to make the student think for himself.

In the Section of Geology and Geography no paper was greeted with more interest or closer attention than that by Prof. J. E. Hilgard, Director of the U.S. Coast Survey, on the relative level of the Gulf of Mexico and the Atlantic Ocean, with remarks on the Gulf Stream and deep-sea temperatures. Its two most essential points are:-(I) The discovery by a most careful series of levels, run from Sandy Hook and the mouth of the Mississippi River to St. Louis, that the Atlantic Ocean at the former point is 40 inches lower than the Gulf of Mexico at the latter point; and (2) that ocean-water at all depths exceeding 1000 fathoms possesses a temperature of nearly $35^{\circ} \mathrm{F}$., because this is the temperature consistent with its greatest density. Should the water become either cooler or warmer, it must expand; which it cannot do on account of the superincumbent pressure.

Prof Henry S. Williams, of Corncll University, in a paper on the influence of geographical and physical conditions in modifying fossil faunas, introduced the exceedingly important subject of the extent to which palæontological evidence is to be regarded as an absolute guide in correlating strata in different regions. Prof. Williams explained a scries of sections, principally in Chemung and Catskill rocks, taken from a number of localities across New York State, and adduced from them abundance of proof that faunas in Devonian times, as at present, changed not only geologically in sequence of time, but also geographically according to the areas of their distribution. The influences which brought about a change in the character of the sediment deposited also manifested themselves in altering the forms of the organisms inhabiting these sediments.

Prof. Alexis Julien of New York communicated the results of a very extended study of the Eozoon canadense from nearly all the localities where it has thus far been found, adding other localities of his own discovery. The result of his investigations led him to decide in favour of the inorganic nature of the socalled fossil, although his ideas in regard to the mode of its formation differ considerably from any heretofore advanced. $\mathrm{He}$ noticed as universal in all localities, that the calcium and magnesium carbonates were very unequally distributed in the Eozoonal limestones, and that there was a large development of pyroxene where the dolomite was least abundant. He moreover observed the constant tendency on the part of pyroxenc to be arranged in layers alternating with either calcite or apatite, as well as abundant evidence that pyroxene passed by hydration into serpentine, a process which could be seen in every stage at any of the localities visited. From these data it was assumed that siliceous waters, permeating limestones originally evenly dolomitic, would cause the local development of pyroxene by the change of the magnesium carbonate into the corresponding silicate. Were it the case, as so often occurs, that this pyroxene was developed in layers, its subsequent alteration to serpentine or loganite would readily account for all the appearances exhi- bited by the Eozoon, without the necessity of appealing to organic agencies.

A large number of papers (forty-three in all) were presented before the Section of Biology; but we regret that in our limited space we can give merely the briefest outlines. The first we may mention was a paper by Mr. D. C. Beyer, on the influence of oxygenated and unoxygenated blood, as well as of blood in various degrees of dilution, on the heart of the frog and terrapin. The paper aimed to prove that it is not concentrated mammalian blood which produces the greatest amount of work either in the heart of the frog or that of the terrapin, but that a certain degree of dilution is necessary.

Dr. C. S. Minot read a paper on biological problems. The author opposed the trinomial system, and considered the present mode of determining species entirely unscientific, and thought that the species should be based on a statistical study of all the variations that are known to occur. Individuals are not always homologous. The only fixed units are (I) cells; (2) the whole series of generations of cells from a single ovum-a cell-cycle. An individual may be almost any fractional part of a cell-cycle. Roughly speaking, the higher the organism the fewer the number of individuals it comprises. The author considered the ovium to be homologous with the encysted protozoon, the radial zone being equivalent to the capsule or cyst of the protozoon, and the contents also homologous.

Prof. E. D. Cope in a paper on the phyllogeny of the Artiodactyle mammals derived from American fossils, considered the derivation of the selenodont dentition from the bunodont as established from a mechanical point of view. The oldest American Artiodactyl (Pantolestes) is bunodont. The modification proceeded as in other ruminants on the lines of the co-ossification of the bones of the legs and feet. The peculiar structure of the carpus in the Oreodontidæ shows them to be, without doubt, the ancestors of the Tragulina. The following table represents the present views of the author on the subject :-

Tritubercular bunodontia (Pantolestidæ). |

Selenodontia. Quadritubercular bunodontia.

$\begin{array}{ccc} & \mid & \mid \\ \text { Hyopotamidx. } & \text { Orcodontidæ. } & \text { Poëbrothcriidæ. } \\ \text { (?) Pecora. } & \text { Tragulina. } & \text { Tylopoda. }\end{array}$

Mr. H. F. Osborne presented observations on the amphibian brain, containing results of microscopic study upon the frog, Menobranchus, Menopoma, and Amphiuma. His method of study was by making series of sections, in their different planes. The relative position of gray and white matter was the same as that found in the spinal cord of these and other vertebrates. The courses of the principal nerve-fibres in their course from the medulla forward to the hemispheres was described, showing the course of the transverse commissures, and pointing out a com missure in the roof of the third ventricle hitherto overlooked. This demonstrated that each brain-segment had its own dorsal commissure. The differences of the cerebellum in the Anura and Urodela were pointed out, and the resemblances of the latter to the mammalian brain were dwelt upon. The pia bloodvessels are all sent in upon the anterior face of the pituitary body. The pineal elements were shown to consist of certain very inconspicuous foldings of the epithelium of the roof of the third ventricle, which have been generally overlooked. These foldings represent what remains of the stalk of the pineal gland.

Mr. S. Garman's paper on Chlamydoselachus, the frillest shark, treated of the internal anatomy of this peculiar shark. The nearest forms are Notanidæ, Hexanchus, and Heptanchus. IIind and fore brain resemble that of foetal sharks; the cartilage is soft : the lateral line is open as in foxtal sharks, and continuer to the end of the tail. The pelvis is twice as long as broad : the nearest resemblance to this is seen in the fotal. Heptanchus. According to the author, the Chlamydoselachus may be a sub order of the Galei.

The next paper was by Prof. E. D. Cope, on the mammalian affinities of Saurians of the Permian epoch, and referred to the detection of mammalian resemblances between Thesomorphus and reptiles of the Permian epoch. Resemblances in the pelvic and scapular arch were pointed out. The quadrate bone was discussed, referring to the theory of Albrecht. The genus 
Clepsydrops shows that it has the mammalian number of bones in its tarsus, and the resemblance was nearest to that found in Platypus anatinus.

Dr. C. H. Merriam read a paper on the hood of the hooded seal (Cystophora cristata), describing it as an inflatable proboscis overhanging the mouth, and extending posteriorly to a point behind the two eyes, lined with nasal mucous membrane, and divided longitudinally by two cartilages. It is not noticeable until the male has reached its fourth year.

In a paper on some points in the development of pelagic teleostean eggs, Mr. G. Brook, Jun., first considered non-pelagic eggs, instancing those of trout, in which the hypoblast originates as an involution of the lower layer upon itself, the space between the layers being quite distinct. In pelagic eggs the process is quite different. Sections of the eggs of Trachinus vipara at this stage show that the parablast of Klein, the intermediate layer of American authors, is made up of a large number of free cells, and nuclei are absorbed from the yolk, which contribute to a very great extent to build up the hypoblast. In this case there is no true invagination. In Motella mustela the origin of the hypoblast is similar to that of Trachinus; but the resulting cells, instead of being quite similar to the original ones, as usual in teleostean eggs, are very much larger, and hexagonal, so that they cannot be derived directly from the lower layer of cells. The author sustained the views of Ryder as regards the segmentation cavity in pelagic eggs. $\mathrm{He}$ also holds that there is no circulation in pelagic embryos before hatching.

Mr. G. Macloskie, in a paper on the dynamics of the insect's test, commenced with a general description of the chitinous skeleton with its in-and out-growths, \&c. The trachex have spinal crenulations, which have been hitherto misunderstood and supposed to be threads; these tracheæ transmit gases directly to the tissues, and the blood is not used for this purpose. The trachea are not directly controlled by muscles, their action depending on the successive production of a partial vacuum, and condensation of air around them.

Prof. A. Hyatt read a paper on the larval theory of the origin of tissue, stating that the building-up of the tissues of the Metazoa is due to a quick and rapid division of cells. Minot's theory that the origin of the sexes is due to the difference in cell elements was supported. The author considered the Planula a more primitive form than the Gastrula. In another paper Prof. Hyatt presented objections to some commonly-accepted views of heredity, asserting that heredity has no need of the gemmule hypothesis or pangenesis, but that it can be equally well understood upon the supposition that the nuclei of cells are the immediate agents of the transmission of characteristics. The author presented the case of a man in Maine, who resembled his mother on one side of his body and his father on the other side, as an illustration of his theory, and he contested the position of Prof. Brooks as regards heredity. In a paper on the structure and affinities of Beatricea, the same author stated that this fossil has had many positions assigned to it in almost all the groups of the Invertebrata, though he himself now thought it a Foraminifer. Thin sections were examined, the structure being found to consist of cells joined by a stolon.

Dr. C. S. Minot presented a paper on the skin of insects. The skin consists of three layers-externally the cuticula, overlying an epithelium, which lies in turn on a sheet of connective tissue; the epithelium is homologous with the epithelium of other animals, and should be so called instead of hypodermis; and dermis, which should be applied to the connective tissue, as it is the homologue of that of vertebrates. The cuticle of caterpillars has not yet been fully described: it consists of two layers, a thick one and a thin one.

In a communication on the development of Limulus, Mr. J. S. Kingsley stated that the account begins after the formation of the blastoderm. At this time there is a single layer of cells surrounding the yolk, in which are scattered nuclei. The mesoblast arises as a single sheet on the ventral surface. Its cells come largely from the blastoderm, but some arise from the yolk nuclei. The mesoblast soon forms two longitudinal layers, one on each side in the neighbourhood of the limbs. The colom is formed by a splitting of the mesoblast, and at first consists of a series of metameric cavities extending into the limbs. The supra-œsophageal ganglion arises by an invagination of the epiblast. The heart arises as two tubes in the somatophore, which later unite. The mesenteron does not appear until after hatching. The amnion of Packard is the first larval cuticle, and bears no resemblance to the amnion of the tracheata. A second cuticle is formed and moulted before hatching. The eyes appear on the dorsal surface at the same time that the limbs appear on the ventral. In these characters Limulus agrees essentially with the Tracheata, and has nothing in common with Crustacea.

Prof. B. G. Wilder, in a paper entitled, "Do the cerebellum and oblongata represent two encephalic segments, or only one?" remarked that most writers had considered two segments to exist. The cephalad of these segments is held to include the cerebellum, together with the portion of the "brain-stem" immediately connected herewith and the latter part of the oblongata. The only writers that have admitted of a single segment caudal of the mesen are Balfour, A. M. Marshall, Owen, and Spitzka. The views of Spitzka were then discussed, concluding with the opinion that sufficient evidence to settle either side was insufficient, and that the question was still open.

Dr. J. A. Ryder presented a paper on the morphology and evolution of the tail of osseous fishes. The caudal fin of fishes is developed in the same way as the median or unpaired fins, from a median fin-fold. After the protocercal stage of the larva is passed, a lower caudal lobe grows out, which is probably the homologue of a second anal fin. The hypotheses which grow out of a consideration of the facts of the development of the tails of fishes are the following:-(r) Whenever heterocercality manifests itself, there is a more or less extensive degeneration of the caudal end of the chordal axis, which began to be somewhat manifest far back in the phylum in such forms as Holocephali, Dipnoi, and Chondropterygians. (2) With the outgrowth of the lower lobes (second anal) the energy of growth tended to push the tip of the chorda upward; the lobe itself arising, probably in consequence of the localisation of the energy of growth and the deposit of organic material at the point, according to the demands of use and effort. (3) Local use and effort, acting as constant stimuli of local growth, carried the heterocercal condition and its accompanying modification of degeneration and reduction still further, as is shown by a study of the homologous elements in the tails of fishes; while use and effort would also continue to augment heterocercality, until the inferior and superior lobes were of about the same length and area, when the morphological characters of the caudal fin would become approximately stable for any one species, as may be shown by measurements of a simple mechanical illustration, in which the interaction and composition of the faces which are brought into action are demonstrated. (4) The mechanical demonstration alluded to above, taken together with the fact that the primitive or ancestral form of the tail, which is typified by a temporary condition in fish larvæ, when the myocomata are rudimentary, but still symmetrical, amounts almost to a demonstration of the principles first laid down by Lamarck, then elaborated by Spencer, and more recently applied to special cases by the author and Prof. Cope.

In a communication on growth and death, Dr. C. S. Minot gave the results of 10,000 measurements of weight of growing guinea-pigs and other animals from birth to maturity. The rate of growth was found to steadily diminish from birth onward ; so that the loss of power begins at once, and continues until death. The common views of death were discussed, and the current conceptions of animal individuality were attacked. The author then referred to the bearing of our present knowledge of senescence upon the theory of life, and the relation of life to a material substratum.

A paper on the osteology of Oveodon was read by Mr. W. B. Scott, in which this genus was said to belong to the Artiodactyla, although there are some strong resemblances to the Suidæ. The vertebræ are ruminant, markedly in the case of the axis. The thoracic vertebræ have long prominent spines, and small bodies slightly amphicœlus. The lumbars, probably five in number, are heavy, with short spines and broad flat transverse processes. The sacrum contains two vertebræ which touch the ileum. The tail is long and slender, and the legs proportionally long. There are a short head and short metapodials, giving the animal a wolf-like appearance. 'The radius and ulna are distinct. The carpus consists of eight bones, including the pisciform. There are short unanchylosed metacarpals. The ungual phalanges are long and pointed, as in Hyopotamus. A rudimentary pollex is present, this being the only Artiodactyl with one.

Mr. J. Struthers, in a paper on finger muscles in Megaptera longimana, and in other whales, records rudimentary flexor and extensor muscles in these animals, and shows that they are more or less used, as the muscular fibres are red and not degenerated.

Dr. G. M. Stemberg described his experimental research 
relating to the etiology of tuberculosis. The author repeated the inoculation experiments of Koch, with similar results. The experiments of Formad to induce tuberculosis in rabbits by introducing into the cavity of the abdomen finely powdered inorganic material, have also been repeated with entirely negative results. The author held that Koch's bacillus was an cssential factor in the etiology of tuberculosis.

Dr. C. E. Bessey, in a paper on the adventitious inflorescence of Cuscuta glomsrata, stated that the examination of young plants shows that the inflorescence is developed from numerous crowded adventitious buds, and not by the repeated branching of axillary flowering branches as commonly stated.

In a paper on the hitherto unknown mode of oviposition in the Carabidæ, Prof. C. V. Riley records habits of Chlenius impunctifrons, traced from the eggs up. The eggs are laid singly, in cells made of mud or clay, on the under surface of leaves.

Mrs. A. B. Blackwell read a paper on the comparative longevity of the sexes. The study was exhaustive, and made on statistics from all parts of the world ; and the greater longevity of woman over man was established. In old countries the females prepondcrate, while males lead in newly settled ones. Up to eighteen years the males are in excess of the females: later the females predominate in numbers.

\section{THE PRIME MERIDIAN CONFERENCE}

THE Prime Meridian Conference at Washington on Monday adopted the Greenwich line as the universal prime meridian. Only one vote--that of St. Domingo-was given against its adoption; but the representatives of France and Brazil declined to votc.

The following details of the session are from the Times Correspondent :-

To the American resolution for adopting the Greenwich line, Mr. Fleming (Canarla) moved an amendment to the effect that the Conference should adopt the I8oth degree of longitude east from Greenwich as the prime meridian; but the other British delegates opposing the proposition it was lost. Señor Valera, the Spanish Minister, said that he had been instructed by his Government, in voting for the meridian of Greenwich, to say that it hoped the metric system of weights and measures would be adopted by England, the United States, and the other nationalities therc represented, as recommended by the Conference at Rome. Gen. Strachey (Great Britain) said that he was authorised to statc that his country had asked to be allowed to join the Metrical Convention, and that the metric system was already recognised by the laws of Great Britain, and was in use for scientific purposes. He could not, however, say that it would be adopted in any circumstances as a popular system of weights and measures throughout England. M. Lefaivre (France) said the Greenwich was not a scicntific meridian, and that it implied no progress in any science, but was merely a commercial standard. Since, therefore, nothing would be gained to science by adopting Greenwich, France could not make a sacrifice of her own meridian, and incur the vast expense consequent upon the adoption of a new one, because she would thereby gain no advantage whatever. Sir William Thomson, who was present as a guest, by the invitation of the Conference, spoke in favour of the choice of Greenwich. He said that it was purely a matter of convenience, and that Greenwich answered the world's convenience better than any other standard meridian. Sir Frederick Evans (Great Britain) presented a statement showing that the shipping tonnage controlled by the Greenwich standard of longitude was about $14, \mathrm{COO}, 000$ tons, and that controlled by the I'aris one only $1,735,000$ tons. From the statement of chart sales, \&c., to nations outside England, he showed how largely the Greenwich measure was used.

The resolution recommending the choice of Greenwich was then adopted, the ayes being $2 \mathbf{r}$, and there being but one naySan Domingo. France and Brazil abstained from voting.

Mr. Rutherford (United States) moved that from the Greenwich meridian the longitude be counted in two directions, up to $180^{\circ}$, the east longitude being " pluts," and the west "minus." The Russian Minister advocated this proposal, but Count Lowenbaupt (Sweden) moved the adoption of the fourth resolution of the Roman Conference for counting longitude continuously through the whole $360^{\circ}$. Herr von Alvensleben (Germany) said that this was a matter of detail, and therefore he should not vote upon it. The British delegates agreed with the Ger- man Minister that this was a matter of detail, and held that it would not make any difference which method was adopted. Señor Juan Pastorian (Spain) stated that he favoured the plan of counting longitude westward continuously round the world.

The discussion was here adjourned.

\section{UNIVERSITY AND EDUCATIONAL INTELLIGENCE}

OXFORD.--The beginning of Michaelmas Term shows that the University and Colleges have not been idle in erecting new buildings for the accommodation of students. The new buildings of Magdalen - to be called the Waynflete Buildings-are ready for occupation, and will be used this term. No one can deny that the most beautiful of Oxford Colleges has added a new ornament to the city in the Waynflete Buildings. The new buildings of Trinity College are rapidly approaching completion. Stretching back from quaint old Kettle Hall in Broad Street, they extend to near the bcginning of the Lime Walk in the College Garden. The open space in front of the Collegeknown as Trinity Green-will now be bounded on the east by these new buildings. The Green will thus become one of the largest "quads" in Oxford. On the north side of the University Museum the new Physiological Laboratory is rising. Its situation is one of the pleasantest in Oxford. That Prof. Burdon-Sanderson is attracting pupils to physiology is a patent fact in Oxford, and one that will be received outside that city with the strongest feeling of satisfaction.

Since last Term we have to deplore the loss of Mark Pattison, Rector of Lincoln Collcge. Mr. Merry, Public Orator in the University, and Fellow and Tutor of the College, has been elected his successor.

The following scheme of lectures and classes has been agreed on by the Board of the Natural Science Faculty :-

In the Department of Physics Prof. Clifton will lecture on the Galvanometer and Methods of Measuring Electric Currents, and on Thermo-Electricity. Prof. Price will lecture on Optics, Physical and Geometrical. Prof. Clifton and Mr. Walker give instruction in Practical Physics in the Clarendon Laboratory. Mr. Walker will give a course on Ouestions incidental to the P'ractical Study of Mechanics and Heat. Mr. Baynes will give a course of lectures at Christ Church on Thermodynamics, and form a class for practical instruction in Magnetic and Electrical Measurements. Mr. Dixon will give a coursc of experimental lectures, on Elementary Heat and Light, at Balliol College. Prof. Pritchard will lecture on Spherical Astronomy, and form a class for practical work in the University Observatory

In the Department of Chemistry Prof. Odling will give a course of lectures on 3-carbon and 4-carbon compounds. Mr. Fisher will lecture on Inorganic, and Dr. Watts on Organic, Chemistry. At Christ Church Mr. Vernon Harcourt will form a class for Volumetric Analysis. Practical instruction in Chemistry is given daily in the Museum Laboratory, and in the Chemical Laboratories at Christ Church and Balliol College. Prof. Gilbert will complete his course on the Constitution of Plants, and will then lecture on the Effects of Manures, Exhaustion and Variations of Season on the Amounts of Produce and on the Composition of Wheat.

In the Morphological Department Prof. Moseley will begin his course of Comparative Anatomy; each lecture will be fol lowed by special demonstrations on the subject of the lecture. Dr. Hickson gives a course on the Morphology of the Vertebrata, each lecture to be followed by special demonstrations. Mr. Barclay Thompson lectures on the Anatomy of the Mam malia: Mr. Jackson on the Fundamental Principles of Comparative Embryology; Mr. Poulton on the Distribution of Animals; Mr. Morgan on Odontography and on Human Osteology. Prof. Westwood will lecture on the Insect Skeleton.

In the Department of Physiology Prof. Burdon-Sanderson will lecture on the Physiology of Circulation and Respiration. Practical instruction will be given in the Laboratory by the Professor, Dr. Dixie, and Dr. Gotch.

Prof. Bayley Balfour will give a course of lectures in the Botanic Garden, on the General Morphology of Plants.

Prof. Prestwich will lecture at the Museum on the Principles and Elements of Geology. Dr. Tylor will lecture on the Intel lectual Development of Mankind.

During the course of the present Michaelmas Term, Scholarships will be awarded in Natural Science at the following Colleges:-At Balliol College, without limitation of age; at 